\title{
Centralizing resident education: From basic training to finishing school
}

\author{
Jonathan C. Nesbitt, MD
}

\author{
From the Department of Thoracic Surgery, Vanderbilt University Medical Center, Nashville, Tenn. \\ Disclosures: Author has nothing to disclose with regard to commercial support. \\ Received for publication Aug 14, 2017; accepted for publication Aug 19, 2017; available ahead of print Sept 26, \\ 2017. \\ Address for reprints: Jonathan C. Nesbitt, MD, Department of Thoracic Surgery, Vanderbilt University Medical \\ Center, 609 Oxford House, 1313 21st Avenue South, Nashville, TN 37232 (E-mail: jcnesbitt@msn.com). \\ J Thorac Cardiovasc Surg 2017;154:2017-8 \\ 0022-5223/\$36.00 \\ Copyright (C) 2017 by The American Association for Thoracic Surgery \\ http://dx.doi.org/10.1016/j.jtcvs.2017.08.066
}

As educators, we continually strive to improve our approaches for resident training. In this issue of the Journal, Moorjani and colleagues ${ }^{1}$ report their 3-year experience with structured, simulation-based courses implemented as complements to clinical training in cardiothoracic surgery in the United Kingdom and the Republic of Ireland. During their 6-year training program, cardiothoracic surgical residents participated in 10 annual courses aligned with the Royal College of Surgeons Cardiothoracic Surgery curriculum that used multiple education methods, including low- and high-fidelity simulation models, and were evaluated through a series of quantitative and qualitative assessments. The program is now in its fourth year. Each trainee attended 2 courses per year at a central location, except in year 4 and year 5 , when they attended 1 course per year. The Society for Cardiothoracic Surgery in Great Britain and Ireland provided support and encouragement for the courses, and quality assurance was also provided by the Department of Education at the Royal College of Surgeons of Edinburgh. Funding was provided through an industry grant. The courses were offered to every nationally appointed cardiothoracic surgical trainee. All 39 cardiothoracic surgical units within the United Kingdom and the Republic of Ireland participated, and faculty from 33 of these units taught the courses. A total of 187 delegates participated in the year-long program. Results of analyses measuring satisfaction, self-confidence, and self-competence after the courses were excellent. All trainees and faculty agreed that these courses should be a mandatory component of all training programs throughout the country.

Unique to this successful venture was the fact that every training program in the United Kingdom and Republic of Ireland was involved. The leaders of the Society for Cardiothoracic Surgery in Great Britain and Ireland recognized the relevance of simulation in surgical training and committed to these dedicated training efforts in a safe learning environment. The advantages of this educational structure are considerable. By briefly removing the trainees from all

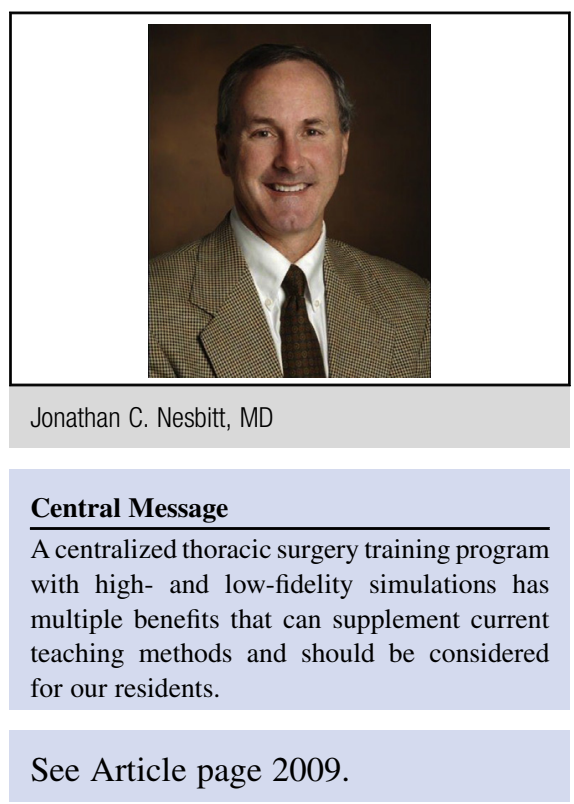

clinical duties for several days at selected intervals, an opportunity was afforded for focused learning, practice, repetition, and teaching by committed faculty.

Our specialty has the distinct advantage of high-fidelity simulation that can very closely replicate the operating room and can provide a venue for teaching and training in fundamental and complex procedures, along with intraoperative events and team training, in a very high value setting. Such programs have been shown to be successful. ${ }^{2-4}$ These simulation programs require significant resources and labor. The costs for supplies and equipment for high-fidelity simulation are high, and justification for investment in resources for individual programs can be difficult; the infrequency of use often does not rationalize the cost. Sharing resources to defray costs, however, can allow communal programs to occur. The concept of a centralized training program, as outlined by Moorjani and colleagues, ${ }^{1}$ is intriguing. At such centers, comprehensive courses can be taught, and basic or advanced technical exercises can be practiced in a controlled, repeatable environment. Bringing all residents together in one setting to expose each of them to a welldefined curriculum helps to ensure consistency in training; common and systematic goals can ensure exposure to essential and key elements.

Moorjani and colleagues, ${ }^{1}$ along with the Royal College, are to be commended for accomplishing their intended goal, and doing so with worthy outcomes. Although the 
program has been successful, the logistics and cost of the enterprise seem likely to be considerable, and a number of questions remain: What are the overall costs? Would individual programs be willing and able to subsidize the costs of sending their residents and faculty to the courses? Will these courses become standards in training? Would individual residency programs allow their residents and faculty to remain away for the duration of each course? How is at-home coverage accomplished for residents who are away for courses? Would each institution provide faculty for the courses to be sustained?

We all should ponder the innovative program set up by Moorjani and colleagues ${ }^{1}$ and consider establishing training sites for our residents and committing time for them to learn these aptitudes. The training tools are at our disposal and have proved their merit. There are practical and feasible ways to use these adjuncts and to incorporate them into our current methodologies, not as replacements but as supplements to our established, successful programs. Through our modification of current training methods to permit residents to have such opportunities, the benefit could be well worth the effort.

\section{References}

1. Moorjani N, Lewis ME, Shah RD, Barnard S, Graham TR, Rathinam S. Implementation of a novel portfolio of structured, curriculum-aligned, simulation-based, cardiothoracic surgery training courses: evolving the delivery of surgical education. J Thorac Cardiovasc Surg. 2017;154:2009-16.

2. Feins RH, Burkhart HM, Conte JV, Coore DN, Fann JI, Hicks GL Jr, et al. Simulation-based training in cardiac surgery. Ann Thorac Surg. 2017;103: 312-21.

3. Burkhart HM, Riley JB, Hendrickson SE, Glenn GF, Lynch JJ, Arnold JJ, et al. The successful application of simulation-based training in thoracic surgery residency. $J$ Thorac Cardiovasc Surg. 2010;139:707-12.

4. Trehan K, Kemp CD, Yang SC. Simulation in cardiothoracic surgical training: where do we stand? J Thorac Cardiovasc Surg. 2014;147:18-24.e2. 